\title{
Application of Polyurethane Foam Loaded with a Schiff Base Ligand for Determination of Trace Amounts of Copper in Water Samples by Flame Atomic Absorption Spectroscopy
}

\author{
Mahdieh Koorehpazan Moftakhar, Mohammad Reza Yaftian*, Samaneh Nahaei, and Abbas Ali Zamani ${ }^{\dagger}$ \\ Phase Equilibria Research Laboratory, Department of Chemistry, Faculty of Science, \\ University of Zanjan, 45371-38791 Zanjan, Iran. EE-mail: yaftian@znu.ac.ir \\ ${ }_{\dagger}^{\dagger}$ Department of Environmental Science, Faculty of Science, University of Zanjan, 45371-38791 Zanjan, Iran.
}

(Received December 5, 2013; Accepted March 12, 2014)

\begin{abstract}
A column solid phase extraction procedure based on modified polyurethane foam (PUF) by a newly synthesized Schiff base ionophore, named 2,2'-\{iminobis[propane-3,1-diylnitrilo(1E)prop-1-yl-1-ylidene]\} diphenol, was developed for preconcentration step of trace amounts determination of copper ions in water samples by atomic absorption flame spectroscopy. The influence of parameters on the adsorption process such as sample $\mathrm{pH}$, amount of modified PUF packed in the column, type and volume of stripping reagent and its flow rate were investigated and optimized. Under optimum experimental conditions, the calibration graph was linear in a relatively wide range $(0.005-210 \mu \mathrm{g} / \mathrm{ml})$ with a limit of detection $0.002 \mu \mathrm{g} / \mathrm{ml}$ of copper. The proposed method allows achieving to a concentration factor of $>133$. The capacity of a column (1.6 cm i.d.) packed by $6 \mathrm{~g}$ of PUF modified by $12 \mathrm{mg}$ of the Schiff base was found to be $247.7( \pm 2.1) \mu \mathrm{g}$ of copper. It was found that the adsorption process was highly selective towards copper ions with respect to some associated metal ions. The presented procedure was successfully applied for determination of copper in some water samples.
\end{abstract}

Key words: Polyurethane foam, Schiff base, Solid phase extraction, $\mathrm{Cu}(\mathrm{II})$, Determination

\section{INTRODUCTION}

Despite the progresses in capability and sensitivity of analytical techniques, determination of trace level of metal ions in environmental, geological, biological or food samples is yet an interesting challenge. ${ }^{1}$ This provokes the investigation and development of new methods for sensitive and precious determination of such chemical species. To this end a separation-preconcentration technique is generally required. Liquid-liquid extraction, ${ }^{2}$ solid phase extraction, ${ }^{3}$ cloud point extraction ${ }^{4}$ and co-precipitation ${ }^{5}$ are among the techniques used for a preconcentration step in trace analysis of environmentally important metal ions. In this subject, the application of solid phase extraction (SPE) procedures has attracted many research groups in last few years. This is particularly due to their advantages such as simplicity, low cost, rapidity, suitable efficiency and environmental aspects.

In solid phase extraction of metal ions, a variety of adsorbents such as ion exchangers, chelating resins and modified $\mathrm{C} 18$ disks have been applied and their potentials were investigated. ${ }^{6}$ Polyurethane foams (PUFs) are among the polymers with a wide variety of applications. They are largely used in home furniture, automobiles, and thermal insula- tion. Due to the presence of polar and non-polar groups in the structure of PUFs, they are able to retain different classes of substances. The large available surface area of the polyurethane foams make them to be suitable for using as stationary phase and as filling materials for column solid phase extraction procedures. Modified PUFs have been used as sorbents for separation-preconcentration of a variety of metal ions. ${ }^{7}$ The first application of PUFs is attributed to the Bowen's study. ${ }^{8}$ Since after, a great number of chemical species, at trace level, was separated and concentrated by using unmodified ${ }^{9-11}$ and a variety of modified polyurethane foams, ${ }^{12-16}$ prior to determination by conventional analytical techniques.

Owing to their coordinating ability for a variety of metal ions, Schiff base ligands have been involved in various analytical investigations for many years. They are a category of important sensory molecules for fabricating of cation ${ }^{17}$ and anion ${ }^{18}$ selective electrodes. Shemirani et al. ${ }^{19}$ have studied the application of bis(2-methoxybenzaldehyde)ethylenediimine as a complexing agent for $\mathrm{Cr}$ (III) ions for enrichment and separation of chromium ions. In addition, various $\mathrm{N}_{2} \mathrm{O}_{2}$ type Schiff base ligands were used as extractants in solvent extraction studies. ${ }^{20}$ These molecules have been also used as modifier of octadecyl silica disks for preconcentration 


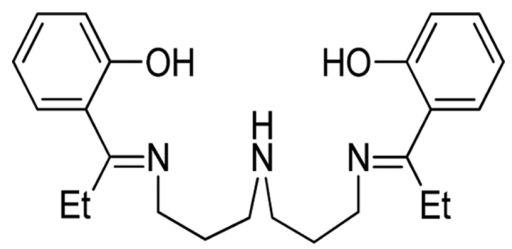

Figure 1. 2,2'-\{iminobis[propane-3,1-diylnitrilo(1E)prop-1-yl-1ylidene]\} diphenol.

and separation of trace amount of metal ions. ${ }^{21}$

Considering the well documented selectivity of nitrogen/oxygen donor ligands towards copper ions ${ }^{22}$ and following to our studies on complexing abilities and analytical applications of $\mathrm{N}_{\mathrm{x}} \mathrm{O}_{\mathrm{y}}$-type Schiff base ligands, ${ }^{17,21,23-26}$ in the present paper we are interested to present the potential of a modified PUF by a Schiff base ligand, named 2,2'-\{iminobis[propane-3,1-diylnitrilo(1E)prop-1-yl-1ylide-ne]\} diphenol (Fig. 1), for preconcentration and determination of $\mathrm{Cu}(\mathrm{II})$ ions in water samples by using FAAS.

\section{EXPERIMENTAL}

\section{Reagents and Solutions}

Ethanol (Merck, Germany), 2-hydroxypropiophenone (Across, USA) and 3,3'-diiminodipropylamine (Merck, Germany) were used for synthesis of the appplied Schiff base. Polyurethane foams were obtained from a furniture manufacturer. Stock copper solution $(1000 \mathrm{mg} / \mathrm{l})$ was prepared by dissolving appropriate amounts of $\mathrm{Cu}\left(\mathrm{NO}_{3}\right)_{2} \cdot 3 \mathrm{H}_{2} \mathrm{O}$ (Merck, Germany) in double distilled water. This solution was standardized complexometrically by EDTA. The highest purity product of nitric acid, phosphoric acid, acetic acid, formic acid and sodium hydroxide (Merck, Germany) were used throughout the work. All other chemical reagents were of analytical reagent grade (Fluka, Switzerland or Merck, Germany) and were used as received.

\section{Apparatus}

${ }^{1} \mathrm{H}$ NMR spectrum was recorded on a FT-Bruker (AVC $250 \mathrm{MHz}$, Germany) spectrometer and data was referenced relative to residual protonated solvent $(7.26 \mathrm{ppm}$ for $\mathrm{CDCl}_{3}$ ). FT-IR spectrum was recorded on a Unicam (Matson 1000, USA) spectrometer. An atomic absorption spectrometer (Varian 220AA, Australia) using air/acetylene flame, was used for metal ion analysis. A Metrohm digital $\mathrm{pH}$ meter (model 780, Switzerland) equipped with a combined glass electrode was used for the $\mathrm{pH}$ adjustments.

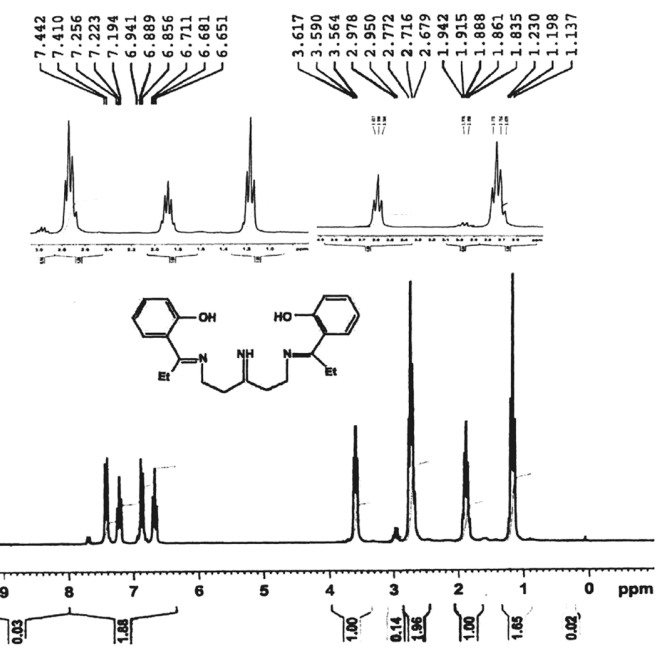

Figure 2. ${ }^{1} \mathrm{H}$ NMR spectrum of the prepared Schiff base.

\section{Synthesis of 2,2'-\{iminobis[propane-3,1-diylnitrilo(1E)- prop-1-yl-1-ylidene]\}diphenol}

A solution of 2-hydroxypropiophenone ( $2 \mathrm{~g}, 13 \mathrm{mmol})$ in ethanol $(30 \mathrm{ml})$ was refluxed with 3,3'-diiminodipropylamine $(0.87 \mathrm{~g}, 6.6 \mathrm{mmol})$ for $2 \mathrm{~h}$. The solvent was evaporated and yellow viscose product was obtained. The purity of the product was checked by thin layer chromatography. Yield, $1.96 \mathrm{~g}(74.8 \%)$. UV-vis $\left(\mathrm{CH}_{2} \mathrm{Cl}_{2}\right): 272,322 \mathrm{~nm}$. IR ( $\left.\mathrm{KBr}\right)$ : $v_{\mathrm{O}-\mathrm{H}}=3419 \mathrm{~cm}^{1}, \mathrm{~V}_{\mathrm{C}-\mathrm{H}}=2970 \mathrm{~cm}^{-1}, \mathrm{~V}_{\mathrm{C}=\mathrm{N}}=1618 \mathrm{~cm}^{-1}, \mathrm{~V}_{\mathrm{C}=\mathrm{C}}$ $=1518 \mathrm{~cm}^{-1}, \mathrm{v}_{\mathrm{C}-\mathrm{O}}=1225 \mathrm{~cm}^{-1}$. Fig. 2 shows ${ }^{1} \mathrm{HNMR}\left(\mathrm{CDCl}_{3}\right)$ of the prepared Schiff base: $\delta(\mathrm{ppm}) 1.14-1.23(\mathrm{t}, 6 \mathrm{H}$, $\left.\mathrm{C}\left(\mathrm{CH}_{2} \mathrm{CH}_{3}\right) \mathrm{NCH}_{2}\right), 1.84-1.94$ (m, $\left.4 \mathrm{H}, \mathrm{NCH}_{2} \mathrm{CH}_{2} \mathrm{CH} 2 \mathrm{NH}\right)$, 2.68-2.77 (m, $\left.4 \mathrm{H}, \mathrm{C}\left(\mathrm{CH}_{2} \mathrm{CH}_{3}\right) \mathrm{NCH}_{2}\right), 3.56-3.62$ (t, $8 \mathrm{H}$, $\mathrm{NCH}_{2} \mathrm{CH}_{2} \mathrm{CH}_{2} \mathrm{NH}$ ), 6.65-7.44 (m, 8, $\mathrm{ArH}$ ).

\section{Preparation of Column}

The bulk polyurethane foam was crushed and powdered. The adsorbent was prepared by mixing $6 \mathrm{~g}$ powdered PUF and $20 \mathrm{ml}$ solution of the studied Schiff base in methanol $(0.06 \% \mathrm{w} / \mathrm{v})$. The mixture was kept in a stoppered glass tube for $5 \mathrm{~h}$, and then the solvent (methanol) was evaporated to dry. A polyrthylene column $(1.6 \mathrm{~cm}$ i.d.) was packed with $6 \mathrm{~g}(3 \mathrm{~cm}$ height) of the prepared adsorbent. Filter papers were used in the bottom and above the modified PUF. The column was washed with $10 \mathrm{ml}$ of diluted nitric acid solution $(0.01 \mathrm{M})$ and then with $20 \mathrm{ml}$ of double distilled water. The general procedure for the extraction of copper ions on the loaded column by modified PUF was as follow: a $100 \mathrm{ml}$ of buffered aqueous solution by sodium acetate/acetic acid $(\mathrm{pH}=5)$ was passed through the column at a flow rate $30 \mathrm{ml} / \mathrm{min}$. The adsorbed copper was stripped with $15 \mathrm{ml}$ solution of EDTA $(0.3 \mathrm{M})$ at optimum flow rate 
(10 $\mathrm{ml} / \mathrm{min})$. This solution was introduced to the flame atomic absorption spectrometer for determination of copper, under recommended conditions proposed by the manufacturer. It was tested that the prepared column was stable for more than 20 times repeated experiments.

\section{RESULTS AND DISCUSSION}

To assess the optimum working conditions for a quantitative determination of copper ions, the parameters affecting the process were verified and optimized.

\section{Effect of pH}

Considering the acidic nature of the Schiff base used for modifying the PUF, the $\mathrm{pH}$ of sample solution can deeply affect the efficiency of the process.

In order to determine the optimal $\mathrm{pH}$ required for a quantitative adsorption of copper ions (initial concentration $5 \mu \mathrm{g} / \mathrm{ml}$ ), the effect of sample solution $\mathrm{pH}$ on the adsorp-

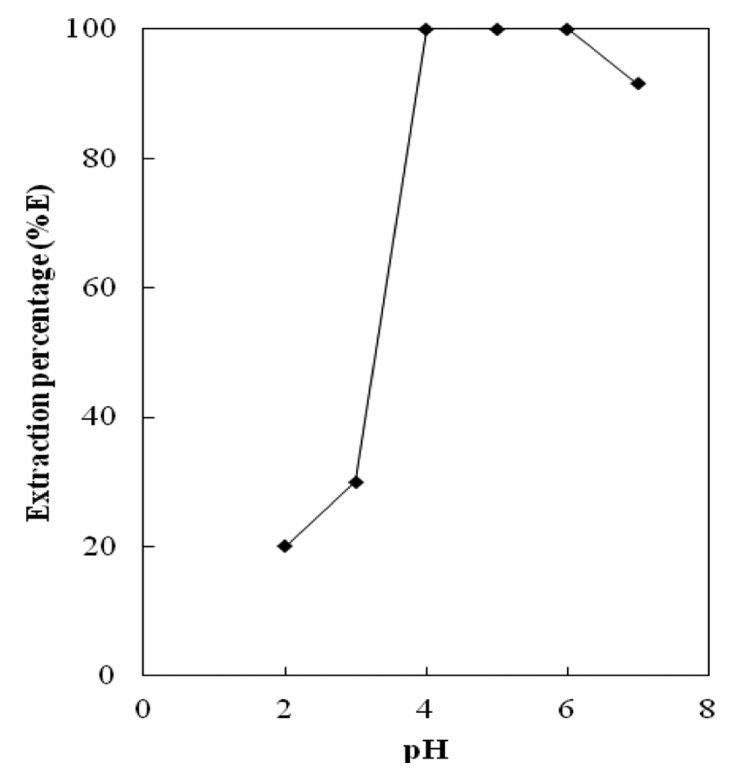

Figure 3. Variation of the extraction efficiency as a function of the sample solution $\mathrm{pH}$. Experimental conditions: sample, $100 \mathrm{ml}$ of solutions containing $5 \mu \mathrm{g}$ of $\mathrm{Cu}(\mathrm{II})$ ions adjusted at different $\mathrm{pH}$; Column, $1.6 \mathrm{~cm}$ i.d containing $6 \mathrm{~g}$ modified PUF with the studied Schiff base (equivalent to $3 \mathrm{~cm}$ height of column); stripping reagent, $15 \mathrm{ml}$ EDTA $(0.3 \mathrm{M})$; sample and stripping reagent flow rates, $30 \mathrm{ml} / \mathrm{min}$ and $10 \mathrm{ml} / \mathrm{min}$, respectively. tion process was evaluated in the range 2 to 8 (Fig. 3). It is seen that a quantitative adsorption $(>90 \%)$ was obtained within the $\mathrm{pH}$ range 4-6. A decrease in extraction efficiency at $\mathrm{pH}$ values higher than 6 can be attributed to the hydroxide formation of copper ions. Thus $\mathrm{pH} 5$ was selected for the subsequent experiments.

\section{Selection of Stripping Reagent}

In order to choose a suitable eluent for desorbing the adsorbed copper ions on the modified PUF, EDTA and nitric acid solutions were examined. It was found that nitric acid solutions $(>0.1 \mathrm{M})$ destroyed the PUF due to the oxidation of the matrix.

Three portions of $5 \mathrm{ml}$ EDTA solution with $0.01-0.3 \mathrm{M}$ concentration were investigated for achieving to suitable desorption efficiency (Table 1). The results show that by passing $15 \mathrm{ml}(3 \times 5 \mathrm{ml})$ of EDTA solution $(0.3 \mathrm{M})$ adjusted at $\mathrm{pH} 5$ and with a flow rate $10 \mathrm{ml} / \mathrm{min}$, quantitative desorption of the copper ions can be achieved.

\section{Amount of Modified PUF Packed in the Column}

The optimum amount of modified PUF in the column was found by examination of various amounts of the adsorbent in the column. The investigated amounts of adsorbent were $1,2,4,5,6,8,12 \mathrm{~g}$ corresponding to $0.5,1,2$, 2.5, 3, 4 and $6 \mathrm{~cm}$ of the occupied height in the column. As it is shown in Fig. 4, columns field with modified PUF beyond $2.5 \mathrm{~cm}(5 \mathrm{~g})$ were capable for a quantitative recovery of copper ions. Thus, a quantity of modified PUF equivalent to $3 \mathrm{~cm}$ height of the column (i.e., $6 \mathrm{~g}$ ) was used for

Table 1. Effect of EDTA concentration on the recovery of the copper ions. ${ }^{\text {a }}$

\begin{tabular}{ccccc}
\hline \multirow{2}{*}{$\begin{array}{c}\text { EDTA } \\
(\mathrm{M})\end{array}$} & \multicolumn{3}{c}{ Recovery $(\%)$} & \multirow{2}{*}{ Total } \\
\cline { 2 - 4 } & $1^{\text {st }} 5 \mathrm{ml}$ & $2^{\text {nd }} 5 \mathrm{ml}$ & $3^{\text {rd }} 5 \mathrm{ml}$ & \\
\hline 0.01 & 36 & 16 & 8 & 60 \\
0.05 & 44 & 19 & 7 & 70 \\
0.07 & 57 & 15 & 11 & 83 \\
0.1 & 62 & 28 & 5.2 & 95.2 \\
0.3 & 75 & 20 & 6 & 101 \\
\hline
\end{tabular}

ather experimental conditions: see the caption Fig. 3, with a column packing height $3 \mathrm{~cm}$.

Table 2. Comparison of modified and unmodified PUF on the extraction efficiency of copper ions

\begin{tabular}{lccccccc}
\hline & \multicolumn{7}{c}{ Extraction (\%) } \\
\hline Height of column (cm) & 0.5 & 1 & 2 & 2.5 & 3 & 4 & 6 \\
Column packed with unloaded PUF & 1.3 & 6.25 & 10 & 12 & 18 & 25 & 30 \\
Column packed with loaded PUF & 30.5 & 50 & 85 & 97 & 100 & 100 & 100 \\
\hline
\end{tabular}

Other experimental conditions: see the caption Fig. 3. 


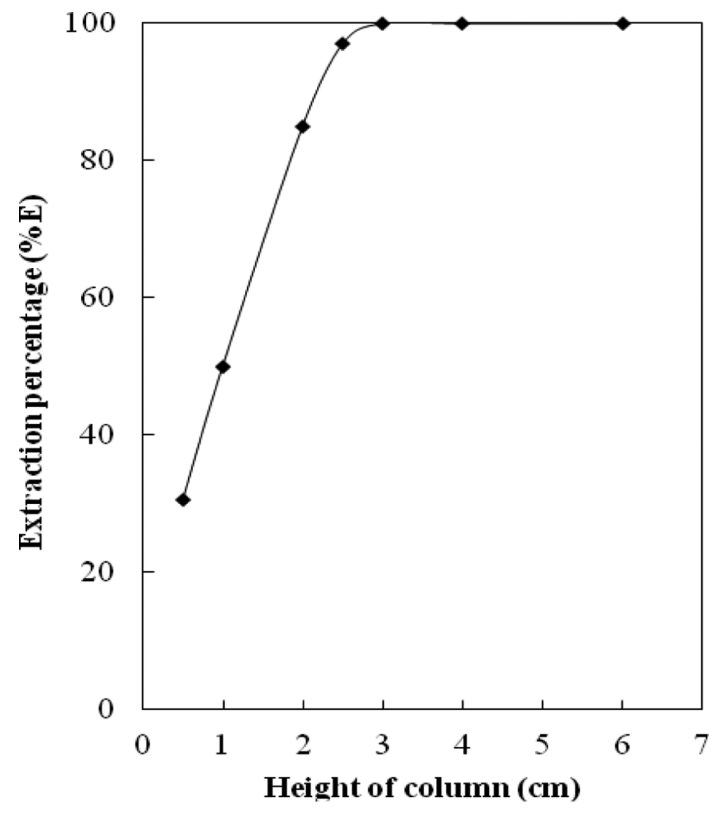

Figure 4. Variation of extraction efficiency as a function of the amount of the modified PUF. pH sample solution, 5; other experimental conditions, except the amount of packing material, are given in the caption Fig. 3.

continuing the experiments.

A comparison of the amount of copper ions adsorbed on the unmodified and modified PUF (Table 2) shows clearly the critical role of the modifier on the efficiency of process.

\section{Effect of Flow Rate on the Extraction Efficiency}

Depends on the kinetics of the process, flow rate of the sample solutions passed through the adsorbent can affect the efficiency of the extraction procedure in continuous solid phase extraction methods. This parameter plays an important role and controls the time dependency of such processes. To elucidate the optimum values of flow rate, a series of extraction experiments was performed by passing sample solutions with different rates in the range $5-100 \mathrm{ml} / \mathrm{min}$ (Table 3). The independency of the adsorption on the sample flow rate can be described by a rapid kinetic of the process. In addition, it was found that desorption of copper ions was not influenced by the elution flow rates in the range of $1.6-28 \mathrm{ml} / \mathrm{min}$.
Based on these results, flow rates 30 and $10 \mathrm{ml} / \mathrm{min}$ were used for extraction and stripping steps, respectively.

\section{Retention Capacity of the Column}

In order to study the maximum adsorption capacity of loaded PUF column, $100 \mathrm{ml}$ of aqueous solution containing $800 \mu \mathrm{g}$ copper was passed through the column. Then the amount of adsorbed copper ions on the sorbent was stripped and determined by flame atomic absorption spectrometry (FAAS). The maximum capacity was found to be $247.7( \pm 2.1) \mu \mathrm{g}$.

\section{Break-through Volume}

The measurement of break-through volume is important in solid phase extraction because this parameter determines the maximum sample volume that can be concentrated by the prepared column.

The break-through volume of the sample solution was tested by using $25,50,100,250,500,1000$ and $2000 \mathrm{ml}$ solutions containing $5 \mu \mathrm{g}$ of copper ions buffered at $\mathrm{pH} 5$. These solutions were passed through loaded column with $6 \mathrm{~g}$ modified polyurethane foam followed by stripping of copper from the adsorbent by $15(3 \times 5) \mathrm{ml}$ solution of $0.3 \mathrm{M}$ EDTA. The analysis of the copper retained on the adsorbent revealed the proposed method can be used for retention of copper ions (5 mg) dissolved in $2000 \mathrm{ml}$ sample solutions. Thus, the break through volume for the proposed SPE method was greater than $2000 \mathrm{ml}$. This means that a concentration factor of higher than 133 can be achieved.

\section{Limit of Detection}

The limit of detection (LOD) of the proposed method based on 3 times of the standard deviation $\left(3 \mathrm{~S}_{b}\right)$ and for 4 replicate measurements of blank solution at optimized conditions was $0.002 \mu \mathrm{g} / \mathrm{ml}$. The linear dynamic range of the proposed method for $\mathrm{Cu}(\mathrm{II})$ ions was found in a wide concentration range of $0.005-210 \mu \mathrm{g} / \mathrm{ml}$.

\section{Extraction of $\mathrm{Cu}$ (II) Ions from Synthetic Samples}

The effect of the presence of divers cations on the preconcentration and determination of $5 \mu \mathrm{g} / \mathrm{ml} \mathrm{Cu}$ (II) ions by the proposed method was studied. Each ion was consid-

Table 3. Result of the investigation of sample and stripping solutions flow rates (in $\mathrm{ml} / \mathrm{min}$ ) on the extraction and recovery (in \%) of copper ions

\begin{tabular}{|c|c|c|c|c|c|c|c|c|}
\hline \multirow{4}{*}{ Process } & \multirow{2}{*}{ Extraction } & F. R. & 5.2 & 9 & 11 & 30 & 50 & 100 \\
\hline & & $\mathrm{E}$ & 100 & 98 & 100 & 103 & 100 & 101 \\
\hline & \multirow{2}{*}{ Stripping } & F. R. & 1.6 & 2.5 & 3.8 & 5 & 10 & 28 \\
\hline & & $\mathrm{R}$ & 100 & 98 & 100 & 102 & 100 & 100 \\
\hline
\end{tabular}

Other experimental conditions: see the caption Fig. 3, with a column packing height 3. F. R.: Flow rate; E: Extraction; R. Recovery. 
Table 4. Recovery of copper ions from binary solutions containing other cations

\begin{tabular}{cccc}
\hline Added cation $\left(\mathrm{M}^{\mathrm{n}+}\right)$ & Ratio of $\mathrm{M}^{\mathrm{n}+}$ to $\mathrm{Cu}^{2+}$ & Copper recovery $(\%)$ & Added cation recovery $(\%)$ \\
\hline $\mathrm{Na}^{+}$ & 1000 & $101.0( \pm 0.6)$ & - \\
$\mathrm{K}^{+}$ & 1000 & $100.0( \pm 0.1)$ & - \\
$\mathrm{Ca}^{2+}$ & 1000 & $100.0( \pm 0.3)$ & $0.5( \pm 0.1)$ \\
$\mathrm{Mg}^{2+}$ & 1000 & $104.0( \pm 0.9)$ & - \\
$\mathrm{Mn}^{2+}$ & 1000 & $102.0( \pm 1.1)$ & $1.7( \pm 0.1)$ \\
$\mathrm{Co}^{2+}$ & 1000 & $100.0( \pm 0.9)$ & $3.8( \pm 0.4)$ \\
$\mathrm{Ni}^{2+}$ & 1000 & $98.2( \pm 0.4)$ & $2.3( \pm 0.2)$ \\
$\mathrm{Cd}^{2+}$ & 1000 & $103.0( \pm 0.8)$ & $6.0( \pm 0.2)$ \\
$\mathrm{Pb}^{2+}$ & 1000 & $100.1( \pm 0.5)$ &
\end{tabular}

The amount of each competing cation was $5 \mathrm{mg}$. Other experimental conditions: see the caption Figure 3, with a column packing height $3 \mathrm{~cm}$.

Table 5. Determination of copper ions in real samples by the proposed preconcentration procedure

\begin{tabular}{lccc}
\hline Sample & $\begin{array}{c}\text { Added } \\
(\mu \mathrm{g})\end{array}$ & $\begin{array}{c}\text { Found }^{\mathrm{a}} \\
(\mu \mathrm{g})\end{array}$ & $\begin{array}{c}\text { Recovery } \\
(\%)\end{array}$ \\
\hline Sea water & 0 & $0.6( \pm 0.1)$ & - \\
(Bandar-e Anzalī, & 5 & $5.5( \pm 0.1)$ & 97.8 \\
Guilan Province) & 10 & $10.7( \pm 0.1)$ & 100.5 \\
\hline \multirow{3}{*}{ Mineral water } & 0 & $0.7( \pm 0.2)$ & - \\
& 5 & $6.0( \pm 0.1)$ & 104.5 \\
\hline Tap water (University & 0 & $10.5( \pm 0.3)$ & 98.0 \\
of Zanjan) & 5 & $0.4( \pm 0.3)$ & - \\
& 10 & $10.4( \pm 0.4)$ & 100.8 \\
\end{tabular}

$\overline{{ }^{a} \text { Mean of } 3 \text { experiments. Standard deviations are given in the parenthe- }}$ ses.

ered as interference when it caused an error greater than $5 \%$ in the determination of copper. As shown in Table 4 the proposed method can be considered as a selective procedure for preconcentration of copper ions.

\section{Analytical Application of the Proposed Method}

To assess the applicability of the method for real samples, it was applied to the extraction-preconcentration and determination of copper ions from 3 different water samples i.e. a tap water (University of Zanjan, Zanjan-Iran), a mineral water and a sample of sea water (Bandar-e Anzalī, Guilan Province-Iran). The results (Table 5) show the suitable performance of the proposed method for the recovery of trace amounts of copper ions from the examined samples.

\section{CONCLUSIONS}

The results of the present study reveal that the Schiff base 2,2'-\{iminobis[propane-3,1-diylnitrilo(1E)prop-1-yl-1-ylidene]\} diphenol can be successfully used as a modifier for spent polyurethane foams. The modified polyurethane foam is suitable sorbent for selective column solid phase extraction-preconcentration of trace amounts of copper(II) ions. A rapid adsorption kinetics and desorption of copper ions, beside using inexpensive and nontoxic materials, allow considering the proposed method as a simple, rapid, lowcost, environmental friendly method for the enrichmentdetermination of copper ions in water samples.

Acknowledgments. Publication cost of this paper was supported by the Korean Chemical Society.

\section{REFERENCES}

1. Pesavento, M.; Alberti, G.; Biesuz, R. Anal. Chim. Acta 2009, 631, 129.

2. Pena-Pereira, F.; Lavilla, I.; Bendicho, C. Spectrochim. Acta 2009, B64, 1.

3. Camel, V. Spectrochim. Acta 2003, B58, 1177.

4. de Almeida Bezerra, M.; Arruda, M. A. Z.; Ferreira, S. L. C. Appl. Spect. Rev. 2005, 40, 269.

5. Bispo, M. S.; da Boa Morte, E. S.; das Graças Andrade Korn, M.; Teixeira, L. S. G.; Korn, M.; Costa, A. C. S. Spectrochim. Acta 2005, B60, 663.

6. Alfassi, Z. B.; Wai, C. M. Preconcentration Techniques; CRC Press: London, 1992.

7. Lemos, V. A.; Santos, M. S.; Santos, E. S.; Santos, M. J. S.; dos Santos, W. N. L.; Souza, A. S.; de Jesus, D. S.; das Virgens, C. F.; Carvalho, M. S.; Oleszczukm, N.; Vale, M. G. R.; Welz, B.; Ferreira, S. L. C. Spectrochim. Acta 2007, B62, 4.

8. Bowen, H. T. M. J. Chem. Soc. A 1970, 1082.

9. Anthemidis, A. N.; Zachariadis, G. A.; Stratis, J. A. Talanta 2002, 58, 831.

10. Sant' Ana, O. D.; Jesuino, L. S.; Cassella, R. J.; Carvalho, M. S.; Santelli, R. E. J. Brazil. Chem. Soc. 2003, 5, 728.

11. de Almeida, G. N.; de Sousa, L. M.; PereiraNetto, A. D.; Cassella, R. J. J. Colloid Interf. Sci. 2007, 315, 63.

12. Lemos, V. A.; dos Santos, W. N. L.; Santos, J. S.; de Car- 
valho, M. B. Anal. Chim. Acta 2003, 481, 283.

13. Gama, E. M.; Lima, A. Da. S.; Lemos, V. A. J. Hazard. Mater. 2006, B136, 757.

14. Moawed, E. A.; El-Shahat, M. F. React. Funct. Polym. 2006, 66,720 .

15. Burham, N.; Abdel-Azeem, S. M.; Shahat, M. F. Anal. Chim. Acta 2006, 579, 193.

16. Lemos, V. A.; Santos, L. N.; Bezerra, M. A. J. Food Composition and Analysis 2010, 23, 277.

17. Emadi, D.; Yaftian, M. R.; Rayati, S. Turk. J. Chem. 2007, $31,423$.

18. Sadeghi, S.; Fathi, F.; Esmaeili, A. A.; Naeimi, H. Sens. Actuator 2006, B114, 928.

19. Shemirani, F.; Dehghan Abkenar, S.; Mirroshandel, A. A.;
Salavati, M.; Rahnama Kozania, R. Anal. Sci. 2003, 19, 1453.

20. Kara, D.; Alkan, M. Microchem. J. 2002, 71, 29.

21. Fathi, S. A. M.; Yaftian, M. R. J. Hazard. Mater. 2009, 164, 133.

22. Hancock, R. D.; Martell, A. E. Chem. Rev. 1989, 89, 1875.

23. Fathi, S. A. M.; Rostamkhani, Sh.; Yaftian, M. R. J. Anal. Chem. 2010, 65, 614.

24. Parinejad, M.; Yaftian, M. R. Iran. J. Chem. Chem. Eng. 2009, 28, 85.

25. Fathi, S. A. M.; Yaftian, M. R. J. Colloid Interface Sci. 2009, 334, 167.

26. Fathi, S. A. M.; Parinejad, M.; Yaftian, M. R. Sep. Purif. Technol. 2008, 64, 1. 